\title{
Investigation on the Professional Identity of Senior High School English Teachers
}

\author{
Xin Wang \\ Foreign Languages Department, Henan University, Kaifeng, Henan, China
}

\begin{abstract}
Teachers' professional identity is pivotal to their professional development. Although studies on teachers' professional identity are extensive, professional identity of senior high English teachers in the Chinese context has been understudied. This paper aims to study professional identity of senior high school English teachers in Henan province of China by investigating 108 teachers from 5 senior high schools and to analyze obstacles to the professional development of senior high school English teachers. Both quantitative and qualitative methods were employed in this paper. It is found that the overall level of professional identity of senior high school English teachers in Henna province of China is average. The obstacles to the professional development of senior high English school teachers in Henan province of China are manifested mainly in the following three aspects: First, Heavy teaching burden give rise to strong pressure on the teachers; second, the deficiency in research ability has a negative influence on the professional development of the English teachers; and third, the unsatisfying working conditions, low pay level and social benefits. Finally, some countermeasures were put forward accordingly.
\end{abstract}

Index Terms - senior high school English teachers, professional identity, professional development, obstacles, countermeasures

\section{INTRODUCTION}

The booming of education can not go without teachers' development which is closely related to teachers' professional identity. No consensus has been reached as regards the definition of "professional identity". According to Kelchtermans (2009), professional identity is concerned with "how teachers see themselves as teachers based on their continuing interaction with their context (Canrinus et al., 2012: 116). Professional identity is not a static process but a dynamic one. It is not only an answer to the question "Who I am at this moment?" but also an answer to the question "What do I want to become?" (Beijaard et al., 2004).

Teacher identity has aroused interest of researchers since the 1990s and has emerged as a separate research area in the last decade (Hao, 2011). Related studies have been witnessed both at home and abroad. The studies abroad can be divided into two categories: those concerned with education in general and those with foreign language education in particular. The studies falling into the first category mainly include: Coldron and Smith (1999) studied the tension in teachers' identity formation, maintaining that a teacher's identity was partly given and partly achieved by active location in social space and that the craft, scientific, moral and artistic traditions were of great significance in educational practice. Using a questionnaire as a tool, Beijaard et al. (2000) explored the way teachers saw themselves as subject matter experts, didactical experts, and pedagogical experts, finding that according to the teachers, professional identity is a combination of the distinct aspects of expertise; Beijaard et al. (2004) classified the previous research on teacher's professional identity into three categories and derived four essential features from these studies. In the end, they pointed out the problems needing to be addressed in the future researches; Jephcote and Salisbury (2009) carried out over a two-year period study to reveal the realities of teachers' working lives and how teachers reconcile competing pressures. Using data collected from Dutch secondary school teachers, Canrinus et al., (2012) studied how the indicators of teachers' sense of their professional identity: self- efficacy, job's satisfaction, occupational commitment and change in teachers' level of motivation were related. They hold that classroom self-efficacy and relationship satisfaction play a key influencing part in the relationship between the indicators. On the topic of teachers' professional identity, different subject matters are taken into consideration. Flores and Day (2006) presented an analysis of the major influences which shaped and reshaped new teachers' identities, disclosing how contextual, cultural and biographical factors interacted to affects the teaching practices of new teachers; Connor (2008) explored secondary school teachers' professional identities and emotional experiences; Through the analysis of the discourses emerged from interviews with a group of Australian primary teachers, McDougall (2010) studied how primary teachers were coming to terms with changing views of literacy. Farrell (2011) discussed the professional role identity of three experienced ESL College teachers in Canada. He identified 16 main role identities of them and classified into three major ones of teacher as manager, teacher as professional, and teacher as acculturator; Pillen et al. (2013) identified six profiles in beginning teachers' professional identity tensions; By dint of the theory of identity development and self-categorization theory, Friesen and Besley(2013) studied the development of first year student teachers' identity from a developmental and social psychological perspective. Adopting a narrative analysis, Ruohotie-Lyhty (2013) compared two newly qualified teachers' professional 
identity formation, showing that the teachers' initial identities and the storytelling process are important to their professional identity formation. By analyzing three stories in a story competition, Schatz-Oppenheimer and Dvir (2014) examined processes in the formation of novice teachers' professional identity. Compared with the studies in the first category, the studies listed into the second category are far less extensive which include: Guided by grounded theory, Abednia (2012)examined Iranian EFL teachers' professional identity reconstruction and observed three major shifts in their professional identities; Drawing on data from interviews, Lee (2013)examined how four EFL writing teachers constructed and negotiated their identities; Employing exploratory research, Scotland (2014)explored how the experienced English language teachers' professional identities were affected, indicating that institutionally imposed pedagogical adaptation may bring about a renegotiation of professional identity for a few teachers. Studies of professional identity at home are mainly composed of the following: Wei and Song (2005) presented literature reviews of overseas studies of teachers' professional identities; Song and Wei (2006) studied the influencing factors on teachers' professional identities in order to evaluate the present state of teachers' professional identities. Fang and Mao (2008) conducted a research on university teachers' professional identity and revealed some results. Hao (2011) interviewed none EFL teachers to explore the changes of their professional identity with in-service doctoral study experience, demonstrating that their professional identities are multi-leveled, achievement-oriented and discipline-focused; Liu (2012) reviewed the relevant literature ranging from more theoretical works to the empirical works, from the broader research development to the relevant local studies in China. Xu (2013)carried out a four-year case study of four EFL teachers on their professional identity change in the first years of teaching, showing that cue-based and exemplar-based imagined identities are changed into rule-based and schema-based practiced identities. Zhang Lian (2013) gave an analysis of the obstacles to college EFL teacher development and proposed coping strategies in accordance with these impediments.

By reviewing the literature, we know clearly that although great progress has been made on teachers' professional identity these years, professional identity of senior high school English teachers has been little studied, much less to say in-depth empirical studies. Thus, the present study undertakes to fill this gap by embarking on a study of professional identity of senior high school English teachers in the Chinese context. The research questions of this study are: 1) How is the overall level of professional identity of senior high school English teachers in Henan province of China? 2) What are the obstacles to the professional development of these teachers? 3) What strategies can wipe out these obstacles?

\section{MethodOLOGY}

\section{A. Participants}

The questionnaire was sent to English teachers from 5 senior high schools in the northern, southern, eastern and western part of Henan province in China. In total, 120 questionnaires were distributed, 108 were returned, which is a response rate of $90 \%$. Male and female teachers participated in the research take the percentage of $67.6 \%$ and $32.4 \%$ respectively. Their ages are of a great variety: $7.4 \%$ were born in the $1960 \mathrm{~s} ; 36.1 \%$ were born in the $1970 \mathrm{~s} ; 49.1 \% \%$ were born in the 1980 s and $7.4 \%$ were born in the 1990s. Their teaching experience varied: $11.1 \%$ had more than 20 years teaching experience; $41.7 \%$ fell in the category 10-19 years of teaching experience; $47.2 \%$ had less than 10 years teaching experience. The academic background of the participants varied: $81.5 \%$ have earned bachelor's degree; $6.5 \%$ have earned master's degree and only $12.0 \%$ received tertiary education. Their academic tiles are of variety: $19.4 \%$ boast senior professional post; $50 \%$ are from professional title 1, 30.6\% are from professional title 2 .

\section{B. Material}

The questionnaire adopted in this study was a revised version of Zhang Lian's (2013) which was composed of three parts. The first part consists of questions about basic working information of the participants: how many lessons they give per week, how many hours they spend to prepare for the lessons per week and so on. The second part of the questionnaire was based on indicators of teachers' professional identities: job satisfaction, occupational commitment, self-efficacy and change in level of motivation (Canrinus et al, 2012). This part consisted of four categories: professional abilities identity, professional effect identity, professional environment identity and professional interpersonal relationship identity, each of which encompassed 3 items. The subjects were asked to what extent they agreed with the items on a 5-point Likert scale (ranging from 1: very dissatisfied, to 5: very satisfied). The third part of the questionnaire consists of three open-ended questions.

\section{RESULTS AND DisCUSSION}

The results and discussion include two parts: the descriptive analysis of the statistical information of the subjects and the analysis of the open-ended questions.

\section{A. Descriptive Analysis of the Statistical Information}

The basic working information of the participants is as follows in Table 1: 
TABLE 1

BASIC WORKING INFORMATION OF THE PARTICIPANTS

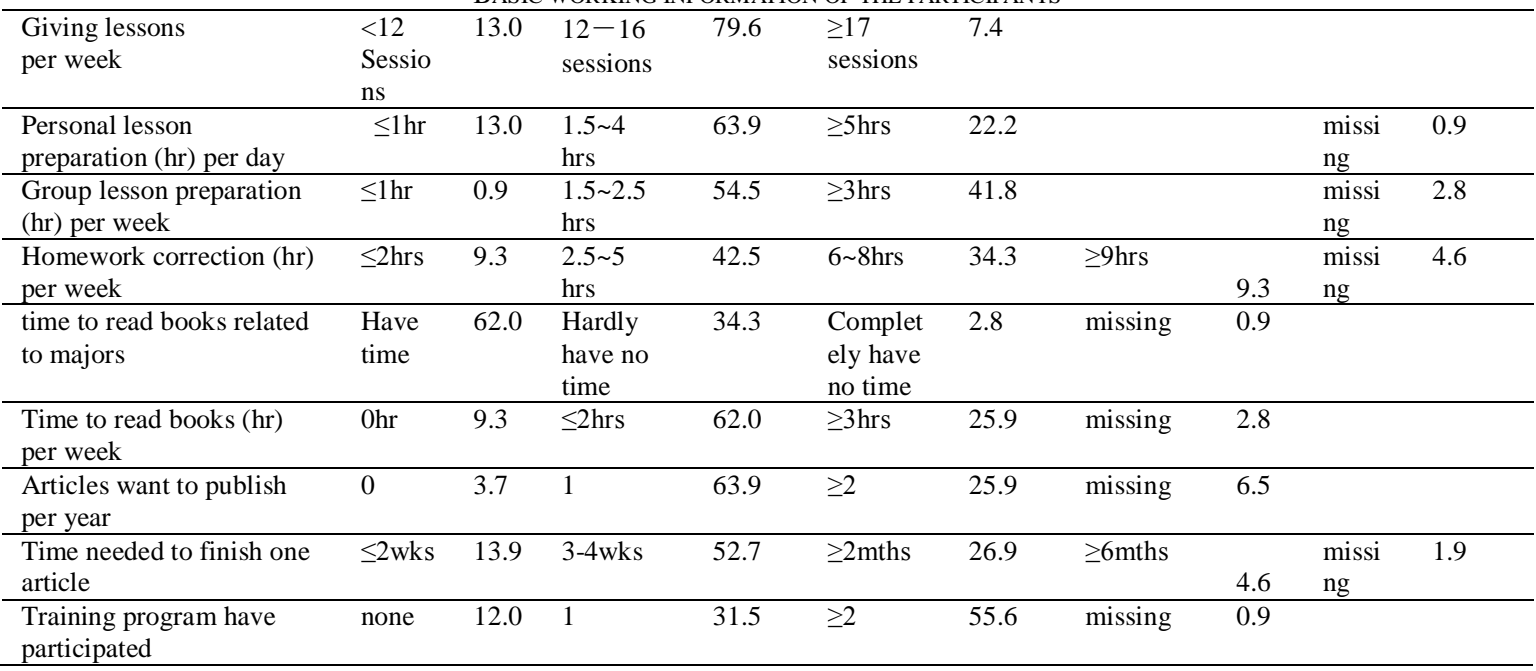

Some characteristics of the working information of the participants can be shown in Table 1:

First, the daily teaching burdens the participants shoulder are heavy. As indicated in Table 1,79.6\% participants give 12-16 sessions lessons per week, $63.9 \%$ participants spend 1.5-4 hours to prepare for lessons per day and it takes $22.2 \%$ more than 5 hours to prepare for lessons. $42.5 \%$ participants spend 2.5-5 hours on homework correcting per week and $34.3 \%$ of them even spend 6-8 hours on homework correcting per week.

Second, the time participants spend reading books related to their majors and doing research is sparse. As demonstrated in Table 1,34.3\% participants said they had no time to read books related to their majors, $62 \%$ of them spend less than 2 hours per week on reading and $9.3 \%$ of them spent less than 1 hour in reading books concerned. This shows that although most participants are research-conscious, they can not allocate enough time to go in for research due to heavy teaching burden. Some teachers are even satisfied with being a teacher only and have no interest to do research.

To summarize, the participants involved are engaged in heavy teaching task. As a result, they do not have enough time to do research, although the majority of the participants are willing to and a few are reluctant to.

As mentioned above, the four categories of teachers' professional identities are professional abilities identity which include English language proficiency level, English teaching ability and teaching methods, professional effect identity which include teaching effect, teaching evaluation and scientific achievements, professional environment identity which include working environment, pay level and social benefits, and professional interpersonal relationship identity which include relationship with students, with colleagues and with school leaders. The participants' professional identity level are reflected to what extent they agree with these items. The results are presented in Table 2:

TABLE 2

PROFESSIONAL IDENTITY DEGREE OF THE PARTICIPANTS

\begin{tabular}{|c|c|c|c|c|c|c|}
\hline Categories & Items & $\begin{array}{l}\text { Very } \\
\text { dissatisfied }(\%)\end{array}$ & $\begin{array}{l}\text { Not very } \\
\text { satisfied (\%) }\end{array}$ & $\begin{array}{l}\text { Indeterminate } \\
(\%)\end{array}$ & $\begin{array}{l}\text { Quite } \\
\text { satisfied (\%) }\end{array}$ & $\begin{array}{l}\text { Very } \\
\text { satisfied } \\
(\%)\end{array}$ \\
\hline \multirow{4}{*}{$\begin{array}{l}\text { professional abilities } \\
\text { identity }\end{array}$} & English & 1.9 & 36.1 & 2.7 & 53.7 & 5.6 \\
\hline & $\begin{array}{l}\text { language } \\
\text { proficiency level }\end{array}$ & & & & & \\
\hline & $\begin{array}{l}\text { English teaching } \\
\text { ability }\end{array}$ & 0 & 18.5 & 3.7 & 72.2 & 5.6 \\
\hline & Teaching method & 0 & 32.4 & 11.1 & 54.5 & 2.0 \\
\hline professional effect & Teaching effects & 0 & 36.1 & 4.6 & 56.5 & 2.8 \\
\hline \multirow[t]{2}{*}{ identity } & $\begin{array}{l}\text { Teaching } \\
\text { evaluation }\end{array}$ & 1.9 & 14.8 & 3.7 & 74.0 & 5.6 \\
\hline & $\begin{array}{l}\text { Scientific } \\
\text { achievements }\end{array}$ & 1.71 & 52.4 & 4.8 & 23.8 & 1.9 \\
\hline $\begin{array}{l}\text { professional } \\
\text { environment }\end{array}$ & $\begin{array}{l}\text { Working } \\
\text { environment }\end{array}$ & 17 & 64.0 & 3.8 & 17.9 & 0.9 \\
\hline \multirow[t]{2}{*}{ identity } & Pay level & 26.9 & 56.5 & 4.6 & 11.1 & 0.9 \\
\hline & Social benefits & 22.2 & 57.4 & 6.5 & 13.0 & 0.9 \\
\hline Professional & With students & 0 & 6.5 & 4.6 & 77.8 & 11.1 \\
\hline interpersonal & With colleagues & 0 & 5.6 & 0.9 & 76.9 & 16.6 \\
\hline relationship identity & $\begin{array}{l}\text { With school } \\
\text { leaders }\end{array}$ & 0 & 27.5 & 19.6 & 46.1 & 6.8 \\
\hline
\end{tabular}

In order to show clearly the professional identity degree of the subjects, the information in Table 2 is represented in increasing order according to the degree of the professional identity in Figure 1: 


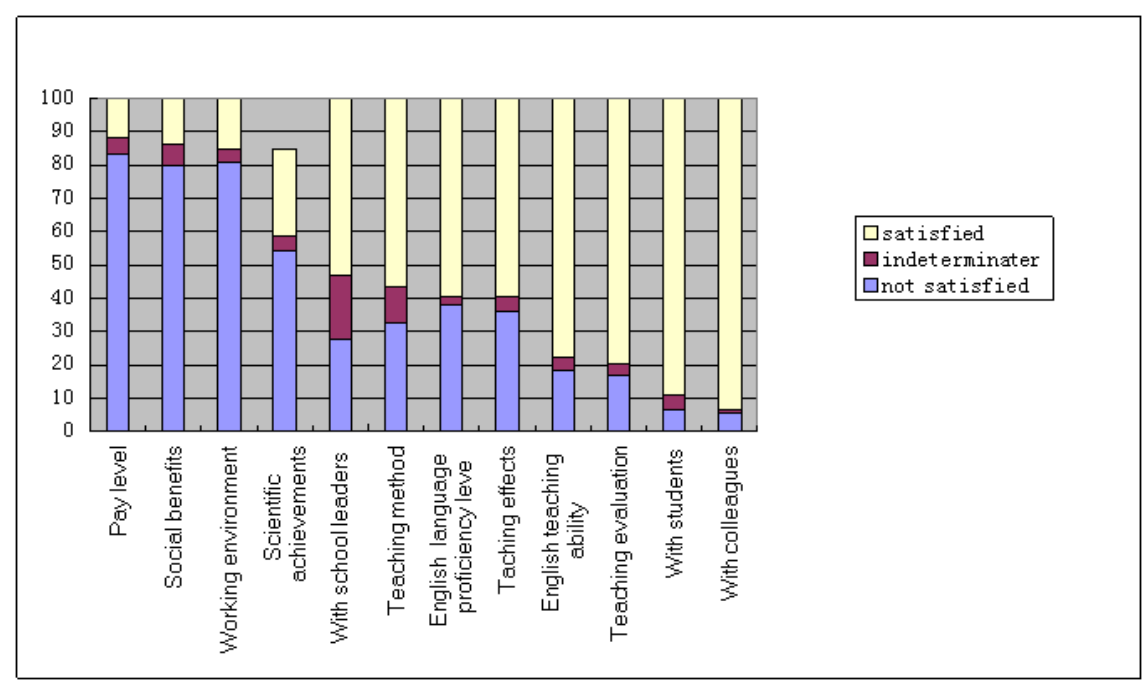

Figure 1 Professional identity degree of the participants

The medium level and standard deviation of the four categories and the overall professional identity are shown in Table 3:

TABLE 3

THE MEDIUM LEVEL (M) AND STANDARD DEVIATION (SD) OF THE FOUR CATEGORIES AND PROFESSIONAL IDENTITY IN GENERAL

\begin{tabular}{llllll}
\hline & $\begin{array}{l}\text { professional } \\
\text { abilities identity }\end{array}$ & $\begin{array}{l}\text { professional } \\
\text { effect identity }\end{array}$ & $\begin{array}{l}\text { professional } \\
\text { environment } \\
\text { identity }\end{array}$ & $\begin{array}{l}\text { Professional } \\
\text { interpersonal } \\
\text { relationship identity }\end{array}$ & $\begin{array}{l}\text { Overall professional } \\
\text { Identity }\end{array}$ \\
\hline $\mathrm{M}$ & 3.386 & 3.197 & 2.133 & 3.767 & 3.121 \\
\hline $\mathrm{SD}$ & 0.186 & 0.410 & 0.089 & 0.318 & 0.251 \\
\hline
\end{tabular}

It is shown that the general professional identity level is medium $(M=3.121)$, the highest professional identity category is professional interpersonal relationship identity $(\mathrm{M}=3.767)$, followed by professional abilities identity $(M=3.386)$, the lowest is professional environment identity $(M=2.133)$. In the professional interpersonal relationship identity, the highest identity item is their relationship with colleagues, followed by their relationship with students, which are $93.5 \%$ and $88.9 \%$ respectively, indicating that the participants are on good terms with their co-workers and their students; in the professional abilities identity, the highest item is teaching evaluation, followed by teaching abilities, which are $79.6 \%$ and $77.8 \%$ respectively, indicating that the participants have laid a solid foundation for the teaching. The lowest item is pay level, followed by social benefits and working environment, which are $12 \%, 13.9 \%$ and $18.8 \%$ respectively.

To summarize, most participants are satisfied with relationship with their students and colleagues but the majority of them are not satisfied with their scientific achievements. The New Curricular Standard (2003) advances that senior high school teachers should strive to become creative, research-oriented teachers. The scientific ability and scientific achievements are important indicators to evaluate a teacher's scientific level. It is generally acknowledged that the scientific abilities of senior high school teachers are very weak, which have a strong impact on their professional identity development. In addition, most participants are not satisfied with their professional working conditions.

\section{B. Qualitative Analysis of Open-ended Questions}

The first question is involved in the participants' understanding of professional identity (What do you think is the meaning and gains of being a senior high school English teacher?), about their requirements of professional development (What do you want to obtain most at the present?) and about their advices and suggestions to their school leaders for them to support their professional development(What advices and suggestions do you have to your school teachers for them to support your professional development?) The answers were written originally in Chinese and then translated into English in writing this paper.

1) What do you think is the meaning and gains of being a senior high school English teacher?

Altogether 86 participants responded to this question, the response rate being $79.6 \%, 4338$ words in total. The most highlighted key word is "the realization of self-worth and social values". Nearly all the participants hold that their biggest gains is the realization of self-worth and social values and being a senior high school English teacher is meaningful because they gain acceptance by the students, the parents of the students and society. As expressed by some participants, "I can provide guidance to my students, so I am very proud of my job", "By imparting to the students the cultures of English-speaking countries, the students' horizon are broadened and I am happy", "The students trust me, love me and understand me and I feel fulfilled". It can be seen clearly that nearly all the participants agree that their work is of great significance and they feel happy and fulfilled to do their job."

2) What do you want to obtain most at the present? 
Altogether 87 participants responded to this question, the response rate being 80.6\%, 4523 words in total. "Opportunities", "time" and "pay level and social benefits raising" are the key words. The exact expression are as follows: "I hope that I can be given a chance to go abroad", "I want to be supplied with training opportunity", "I want to get the opportunities to initiate a project", "What I desire most is for my pay and social benefits to be raised."

3) What advices and suggestions do you have to your school teachers for them to support their professional development?

Altogether 83 participants responded to this question, the response rate being $76.9 \%$, 3311words in total. The key word of the response is "hope". The exact words of the participants are "I hope school leaders can take into consideration the teachers' health, both physical and mental", "I sincerely hope that the working conditions of the teachers can be improved", "I hope that school leaders can increase the donation to English teaching"," I really hope that I can be given opportunities to learn from professionals", "The school leaders should exercise democracy so as to listen to the hearts of the common teachers".

By the analysis above, we hold that the obstacles to the professional development of senior high school English teachers in Henan province of China are as follows:

1) Heavy teaching burden give rise to strong pressure on the teachers. The statistical information indicate that the senior high school English teachers are under great pressure since on the one hand, they have to give many lessons per week, and on the other hand, they are obliged to publish papers to upgrade their academic titles. Consequently, the teachers are experiencing fatigue physically and spiritually.

2) The deficiency in research ability has a negative influence on the professional identity development of the teachers. Though the majority of the participants are in great need of some opportunities to receive further training, yet they are provided litter chance. With no Doubt, many teachers complained that their teaching methods could not keep pace with the demand of the new curricular reform.

3) The unsatisfying working conditions, low pay level and social benefits. Though most teachers regard teaching as a glorious job, they maintained that they had overpaid but gained less. A few of them even want to change their jobs.

\section{CONCLUSION}

This paper endeavors to study professional identity of senior high school teachers in Henan province of China by investigating 108 teachers from 5 senior high schools and to analyze the obstacles to the professional development of senior high school English teachers in Henan province of China. It is found that the overall level of professional identity of senior high school English teachers in Henan province of China is medium. There are three obstacles to the professional development of senior high school English teachers in Henan province of China: First, Heavy teaching burden give rise to strong pressure on the teachers; second, the deficiency in research ability have a negative influence on the professional identity development of the teachers; and third, the unsatisfying working conditions, low pay level and social benefits.

In accordance with the obstacles this paper discussed, we believe that in order to facilitate the professional development of senior high school English teachers in Henan province of China, all the parties - the teachers, the schools and society alike should combine their efforts. Otherwise, the professional development of the teachers is just empty talks. Therefore, this paper offers some advices and suggestions as follows:

1) The senior high schools should have a change of their roles and pursue humanized management. They are advised to stand in the shoes of the teachers. They are supposed to care for the teachers, do whatever possible to improve their working conditions and raise their pay level and social benefits.

2) Senior high schools should combine with universities to set up training bases. The middle school teachers and college teachers should form "research community" and at the same time function as the true subjects of teacher education. In this way can the theory and practice be integrated. The "national training plan" is a good example carried out in China. In the training, importance should be attached to the real effect of the training rather than to the formality.

3) The development of the teachers depends on internal as well as external factors. The external factors take effect only through the internal factors. The senior high schools English teachers should strengthen their sense of development and take initiatives to enhance their abilities, especially their capacities for scientific research.

The professional development of the teachers is the only way to ensure high educational quality. As said by Wu (2008), only when teachers take education as an indispensable part of their life and fully control the external factors, the teaching job will be an enjoyment. Without the joint effort of the above-mentioned parties, it is impossible to realize this ideal.

\section{ACKNOWLEDGEMENT}

This author is indebted to the grant of the following foundation items: Teachers' Educational Project in Henan Province (project number: 2013-JSJYYB-007); Educational and Scientific "the Twelfth Five-Year Plan" Project in Henan Province (project number: [2011]-JKGHAC-0140*). 


\section{REFERENCES}

[1] Abednia, A. (2012). Teachers' Professional Identity: Contributions of a Critical EFL Teacher Education Course in Iran. Teaching, 28 (5), 706-717.

[2] Beijaard, D., N. Verloop \& J. D. (2000). Vermunt. Teachers' Perceptions of Professional Identity: An Exploratory Study from a Personal Knowledge Perspective. Teaching and Teacher Education, 16, 749-764.

[3] Beijaard, D., P. C. Meijer \& N. Verloop. (2004). Reconsidering Research on Teachers' Professional Identity. Teaching and Teacher Education, 20, 107-128.

[4] Canrinus, E. T., M. Helms-Lorenz, D. Beijaard, J. Buitink \& A. Hofman. (2012). Self-efficacy, Job satisfaction, Motivation and Commitment: Exploring the Relationships between Indicators of Teachers' Professional Identity. European Journal of Psychology of Education, 27, 115-132. doi: 10.1007/s10212-011-0069-2

[5] Coldron, J. \& R. Smith. (1999). Active Location in Teachers' Construction of Their Professional Identities. Journal of Curriculum Studies, 31(6), 711-726.

[6] Fang, M. J \& Mao, J. P. (2008). A Research on University Teachers' Professional Identity. Journal of Higher Education, 7 , 56-61.

[7] Farrel, S. C. T. (2011). Exploring the Professional Role Identities of Experienced ESL Teachers through Reflective Practice. System, 39, 54-62. doi:10.1016/j.system.2011.01.012

[8] Flores, A. M \& C. Day. (2006). Contexts Which Shape and Reshape New Teachers' Identities: A Multi-Perspective Study. Teaching, 22 (2), 219-232.

[9] Friesen, D.M \& S. C. Besley. (2013).Teacher Identity Development in the First Year of Teacher Education: A Developmental and Social Psychological Perspective. Teaching and Teacher Education, 37(6), 23-32. doi: 10.1016/j.tate.2013.06.005

[10] Hao, Cai hong. (2011). Changes and Characteristics of EFL Teachers' Professional Identity: The Cases of Nine University Teachers. Chinese Journal of Applied Linguistics (Quarterly), 1, 3-21.

[11] Jephcote, M \& J, Salisbury.(2009). Further Education Teachers' Accounts of Their Professional Identities. Teaching, 25 (7), 966-972.

[12] Kelchtermans, G. (2009). Who I Am In How I Teach Is the Message: Self-understanding, Vulnerability and Reflection. Teachers and Teaching, 15, 257-272.

[13] Lee, I. (2013). Becoming a Writing teacher: Using "Identity" as an Analytic Lens to Understand EFL Writing Teachers' Development. Journal of Second Language Writing, 22,330-345. doi: 10.1016/j.jslw.2012.07.001

[14] McDougall, J. (2010). A Crisis of Professional Identity: How Primary Teachers Are Coming to Terms with Changing Views of Literacy. Teaching and Teacher Education, 26, 679-687. doi:10.1016/j.tate.2009.10.003

[15] O'Connor, E. K. (2008). "You choose to care": Teachers, emotions and professional Identity. Teaching, 24 (1), 117-126.

[16] Pillen, M. T. et al. (2013). Profiles and Change in Beginning Teachers' Professional Identity Tensions. Teaching and Teacher Education, 34, 86-97. doi: 10.1016/j.tate.2013.04.003

[17] Ruohotie-Lyhty, M. (2013). Struggling for a Professional Identity: Two Newly Qualified Language Teachers' Identity Narratives during the First Years at Work. Teaching and Teacher Education, 30, 120-129. doi: 10.1016/j.tate.2012.11.002

[18] The Ministry of Education of the People's Republic of China (experimental). (2003). English Curriculum Standard in General Senior High Schools (Experimental). China: People's Education Press.

[19] Schatz-Oppenheimer, O \& N, Dvir. (2014) .From Ugly Duckling to Swan: Stories of Novice Teachers. Teaching and Teacher Education, 37, 140-149. doi: 10.1016/j.tate.2013.10.011.

[20] Scotland,J.(2014). Operating in Global Educational Contact Zones: How Pedagogical Adaptation to Local Contexts May Result in the Renegotiation of the Professional Identities of English Language Teachers. Teaching and Teacher Education, $37,33-43$. doi:10.1016/j.tate.2013.09.002

[21] Song, G. W \& Wei, S. H. (2006). A Study on Influencing Factors on Teachers' Professional Identity. Psychological Development and Education, 1, 80-86.

[22] Wei, S. H \& Song, G. W. (2005). An Overview of Western Studies of Teachers' Professional Identity. Comparative Education Review, 5, 61-66.

[23] Wu, Yi'an. (2008). A Study of Effective EFL Teachers' Professional Development. Foreign Languages Research, 3, 29-38.

[24] Xu, Hao. (2013). From the Imagined to the Practiced: A Case Study on Novice EFL Teachers' Professional Identity Change in China. Teaching and Teacher Education, 31, 79-86. doi: 10.1016/j.tate.2013.01.006

[25] Zhang, Lian. (2013). Perceived Impediments to College EFL Teacher Development and Coping Strategies: A Case Study. China Foreign languages, 1, 81-88.

Xin Wang was born in Henan province in 1981. She received her bachelor's degree and master's degree in English Linguistics and Literature from Henan University in 2004 and 2007 respectively.

She is now an English lecturer in Foreign Languages Department, Henan University, China. Her research interests are second language acquisition and cognitive linguistics. 